\title{
Gender Differences in Research Project Grants and R01 Grants at the National Institutes of Health
}

Amna Mohyud Din Chaudhary ${ }^{1}$, Sadiq Naveed ${ }^{2}$, Beenish Safdar ${ }^{3}$, Sundas Saboor ${ }^{4}$, Muhammad Zeshan ${ }^{5}$, ${ }^{6}$, Faisal Khosa ${ }^{7}$

1. Psychiatry, Nishtar Medical College \& Hospital, Multan, PAK 2. Psychiatry, institute of Living, Hartford, USA 3. Graduate Medical Education, John T. Mather Memorial Hospital, Northwell Health, Port Jefferson, USA 4. Psychiatry, Khyber Medical College, Peshawar, PAK 5. Psychiatry/Child and Infant Psychiatry, Rutgers Medical School, Newark, USA 6. Psychiatry, Bronx Lebanon Hospital, Icahn School of Medicine at Mount Sinai, Bronx, USA 7. Radiology, Vancouver General Hospital, Vancouver, CAN

Corresponding author: Muhammad Zeshan, zeshan.muhammad@outlook.com

\section{Abstract}

\section{Objectives}

The National Institutes of Health (NIH), which is the world's largest funding source for research, offers various types of competitive grants depending on the duration, research type, and budget. The Research Project Grant (RPG) is the oldest mechanism for grant allocation that is used by the NIH. In this study, we explored the gender trends of NIH RPGs and R01 grants over the last two decades.

\section{Methods}

By utilizing the NIH Research Portfolio Online Reporting Tool (RePORT), data for gender were extracted, and the percentage of women as RPGs Investigators, R01-equivalent grant including R01 type 1 and type 2 grant awardees, from 1998 to 2019 were tabulated. The absolute change was calculated.

\section{Results}

From 1998 to 2019, the percentage of female RPG awardees has increased. However, the success rates for female RPG applicants have decreased during the same period. The funding and success rates for new R01 awards have been similar for both men and women, but women have been less successful at the renewal of R01-equivalent awards.

\section{Conclusion}

Gender disparity exists in awardees of higher RPGs, including the R01 award. This highlights the need for further actions to ensure gender parity in grant allocations at the $\mathrm{NIH}$.

Review began 04/30/2021 Review ended 05/06/2021 Published 05/10/2021

\section{(๑) Copyright 2021}

Chaudhary et al. This is an open access article distributed under the terms of the Creative Commons Attribution License CC-BY 4.0., which permits unrestricted use, distribution, and reproduction in any medium, provided the original author and source are credited.
Categories: Medical Education, Other

Keywords: gender, gender disparity, nih funding gender disparity, female researcher, academic productivity, research career, r01 grant, r01-equivalent grant, nih funding

\section{Introduction}

Women have narrowed the gender gap with men among biomedical science degree holders, but they are lagging behind in academic ranks and leadership positions [1-3]. Women were $49 \%$ of all $\mathrm{PhD}$ degree awardees in biological sciences in 2005, and it increased to 52\% in 2010 [4]. However, female assistant professors with a biology PhD constituted only 44\% of the faculty in 2015 [5]. Similar discrepancies between PhD holders and faculty representation also persist in academic medicine [2,6,7], professional medical societies [8-10], and editorial boards of medical journals [11,12]. The National Institutes of Health (NIH), which is the world's leading source of public funding for biomedical research, receives disproportionally a lower number of newer grant applications from women [13]. Furthermore, less than one-third of NIH research grantees are comprised of women, even though their success rates are similar for obtaining first grants compared to men [14].

The NIH achieves its goal of expanding biomedical research by supporting research in different domains through the administration of various grant types [15]. These grants are pivotal for scientists to carry out research activities, run their laboratories, and apply for promotions and tenure [16]. The NIH also plays a pivotal role in the contribution to the nation's economy by creating jobs and increasing the demand for local services as well as serve as a foundation for the United States (U.S.) biomedical industry. It is estimated that approximately every US dollar of NIH funding generates $\approx \$ 2.21$ in local economic growth [17]. 
Various funding opportunities are available through the NIH. The Research Project Grant (RPG) is the original and oldest mechanism of grant used by the NIH. The NIH grants are specified by an activity code representing the type of research being funded [13]. The R01 award is the "gold standard" of research awards and provides funding and support for health-related research and development based on the mission of the NIH [17]. The NIH has two types of applications for R01 grants including R01 New (Type 1) and R01 Renewal (Type 2) [18].

It is critical to explore the trends of gender disparity in NIH funding to address academic and scholarly diversity. In our study, we explored the trends of the NIH R01 grant and characterized the potential explanations for any existing gender differences. We also analyzed NIH funding trajectories over time, comparing gender differences for the early stage of women's careers and whether they continue to stay funded at the same rates as men. We explored the differences in funding trajectories for men and women from 1998 to 2019, using NIH grant records for investigators who received a major NIH RPG for the last two decades.

\section{Materials And Methods}

Our methodology has been validated in recent publications [19]. This retrospective study did not require Institutional Ethics Board approval as the data were exported from publicly available data at the NIH Research Portfolio Online Reporting Tools (RePORT) - NIH Data Book. We utilized the NIH grant and funding reports for the consecutive fiscal years 1998 to 2019.

\section{Variables}

The percentage of women receiving RPGs, and the differences in the annual applications, awards, and success rates for the RPGs by gender were extracted and tabulated. Similarly, the percentage of women receiving the R01-equivalent awards and the success rates by type of application (Type 1/New or Type 2/Renewal) were compared over the study period to examine the temporal trends. The average funding of R01-equivalent grants in current and constant dollars was also compared between genders.

\section{Data analysis}

We analyzed the categorical data by gender and its temporal trend by year and across RPGs and R01 awards. The award success rate was compared for RPGs and R01-equivalent grants, and absolute change (\%) was calculated from the years 1998 to 2019. Tables were created to highlight and compare the gender percentages for each category and year.

\section{Results}

The contribution and involvement of women in research development from the year 1998 to 2019 were tabulated (Table 1). There has been a substantial increase in the overall percentage of women receiving RPGs at the NIH over the last 21 years and it is continually increasing. There was an absolute increase of 11\% from 1998 to 2019 (Table 1). 


\section{Cureus}

\begin{tabular}{|c|c|c|c|}
\hline Year & Women & Men & Percentage to Women \\
\hline 1998 & 5,983 & 20,850 & $22 \%$ \\
\hline 1999 & 6,568 & 22,261 & $23 \%$ \\
\hline 2000 & 7,048 & 23,514 & $23 \%$ \\
\hline 2001 & 7,586 & 24,764 & $23 \%$ \\
\hline 2002 & 8,043 & 26,082 & $24 \%$ \\
\hline 2003 & 8,696 & 27,291 & $24 \%$ \\
\hline 2004 & 9,091 & 27,918 & $25 \%$ \\
\hline 2005 & 9,348 & 27,595 & $25 \%$ \\
\hline 2006 & 9,346 & 27,116 & $26 \%$ \\
\hline 2007 & 9,519 & 27,339 & $26 \%$ \\
\hline 2008 & 9,568 & 26,582 & $26 \%$ \\
\hline 2009 & 9,523 & 25,661 & $27 \%$ \\
\hline 2010 & 9,564 & 25,492 & $27 \%$ \\
\hline 2011 & 9,702 & 25,113 & $28 \%$ \\
\hline 2012 & 9,882 & 24,746 & $29 \%$ \\
\hline 2013 & 9,514 & 23,861 & $29 \%$ \\
\hline 2014 & 9,473 & 23,208 & $29 \%$ \\
\hline 2015 & 9,703 & 23,149 & $30 \%$ \\
\hline 2016 & 10,150 & 23,802 & $30 \%$ \\
\hline 2017 & 10,581 & 24,210 & $30 \%$ \\
\hline 2018 & 11,629 & 25,008 & $32 \%$ \\
\hline 2019 & 12,539 & 25,915 & $33 \%$ \\
\hline \multicolumn{3}{|c|}{ Absolute Change (\%) } & $+11 \%$ \\
\hline
\end{tabular}

TABLE 1: Research Project Grants: Awards by Gender and Percentage to Women. (For the last fiscal year displayed, Research Project Grants are defined as activity codes DP1, DP2, DP3, DP4, DP5, P01, PN1, PM1, R00, R01, R03, R15, R21, R22, R23, R29, R33, R34, R35, R36, R37, R61, R50, R55, R56, RC1, RC2, RC3, RC4, RF1, RL1, RL2, RL9, RM1, UA5, UC1, UC2, UC3, UC4, UC7, UF1, UG3, UH2, UH3, UH5, UM1, UM2, U01, U19, and U34. Research projects were first coded to the NLM in the fiscal year 2007. Not all of these activities may be in use by the NIH every year.)

NLM, National Library of Medicine; NIH, National Institutes of Health

In the comparison of the competing applications and award success rate, there was a smaller decrease in the observed success rates for female RPG applicants at $-9 \%$ compared to $-12 \%$ in their male counterparts (Table 2). 


\section{Cureus}

\begin{tabular}{|c|c|c|c|c|c|c|}
\hline \multirow{2}{*}{ Year } & \multicolumn{3}{|l|}{ Women } & \multicolumn{3}{|l|}{ Men } \\
\hline & Applications & Awards & Success Rate & Applications & Awards & Success Rate \\
\hline 1998 & 5,763 & 1,715 & $30 \%$ & 17,726 & 5,698 & $32 \%$ \\
\hline 1999 & 6,385 & 1,977 & $31 \%$ & 19,114 & 6,457 & $34 \%$ \\
\hline 2000 & 6,851 & 2,046 & $30 \%$ & 20,025 & 6,600 & $33 \%$ \\
\hline 2001 & 7,188 & 2,229 & $31 \%$ & 20,451 & 6,754 & $33 \%$ \\
\hline 2002 & 7,808 & 2,246 & $29 \%$ & 21,699 & 7,045 & $32 \%$ \\
\hline 2003 & 9,175 & 2,733 & $30 \%$ & 24,992 & 7,564 & $30 \%$ \\
\hline 2004 & 10,873 & 2,597 & $24 \%$ & 29,453 & 7,406 & $25 \%$ \\
\hline 2005 & 11,739 & 2,602 & $22 \%$ & 30,696 & 6,938 & $23 \%$ \\
\hline 2006 & 12,355 & 2,452 & $20 \%$ & 32,329 & 6,599 & $20 \%$ \\
\hline 2007 & 13,131 & 2,706 & $21 \%$ & 32,971 & 7,294 & $22 \%$ \\
\hline 2008 & 12,489 & 2,706 & $22 \%$ & 30,271 & 6,656 & $22 \%$ \\
\hline 2009 & 12,894 & 2,546 & $20 \%$ & 29,686 & 6,264 & $21 \%$ \\
\hline 2010 & 13,956 & 2,673 & $19 \%$ & 31,307 & 6,703 & $21 \%$ \\
\hline 2011 & 15,126 & 2,587 & $17 \%$ & 33,657 & 6,104 & $18 \%$ \\
\hline 2012 & 15,417 & 2,695 & $17 \%$ & 34,685 & 6,214 & $18 \%$ \\
\hline 2013 & 14,969 & 2,408 & $16 \%$ & 32,696 & 5,742 & $18 \%$ \\
\hline 2014 & 15,428 & 2,777 & $18 \%$ & 33,477 & 6,268 & $19 \%$ \\
\hline 2015 & 15,798 & 2,891 & $18 \%$ & 34,396 & 6,497 & $19 \%$ \\
\hline 2016 & 16,789 & 3,159 & $19 \%$ & 35,370 & 7,028 & $20 \%$ \\
\hline 2017 & 16,954 & 3,186 & $19 \%$ & 34,930 & 6,763 & $19 \%$ \\
\hline 2018 & 17,651 & 3,687 & $21 \%$ & 35,027 & 7,164 & $20 \%$ \\
\hline 2019 & 17,857 & 3,705 & $21 \%$ & 34,844 & 7,086 & $20 \%$ \\
\hline \multicolumn{3}{|c|}{ ge (\%) } & $-9 \%$ & \multicolumn{2}{|c|}{ Absolute Change (\%) } & $-12 \%$ \\
\hline
\end{tabular}

TABLE 2: Research Project Grants: Competing Applications, Awards, and Success Rates, by Gender. (For the last fiscal year displayed, Research Project Grants are defined as activity codes DP1, DP2, DP3, DP4, DP5, P01, PN1, PM1, R00, R01, R03, R15, R21, R22, R23, R29, R33, R34, R35, R36, R37, R61, R50, R55, R56, RC1, RC2, RC3, RC4, RF1, RL1, RL2, RL9, RM1, UA5, UC1, UC2, UC3, UC4, UC7, UF1, UG3, UH2, UH3, UH5, UM1, UM2, U01, U19, and U34. Research projects were first coded to NLM in the fiscal year 2007. Not all of these activities may be in use by the NIH every year.)

NLM, National Library of Medicine; NIH, National Institutes of Health

Women had a significant increase from 5,203 to 9,263 between 1998 and 2019 as the recipients of R01 grants (Table 3). The percentage of total R01 grants received by women increased by $9 \%$ in the same period. 


\section{Cureus}

\begin{tabular}{|c|c|c|c|}
\hline Year & Women & Men & Percentage to Women \\
\hline 1998 & 5,203 & 18,297 & $22 \%$ \\
\hline 1999 & 5,665 & 19,471 & $22 \%$ \\
\hline 2000 & 5,982 & 20,348 & $22 \%$ \\
\hline 2001 & 6,269 & 21,019 & $22 \%$ \\
\hline 2002 & 6,498 & 21,638 & $23 \%$ \\
\hline 2003 & 6,825 & 22,057 & $23 \%$ \\
\hline 2004 & 7,025 & 22,209 & $23 \%$ \\
\hline 2005 & 7,066 & 21,841 & $24 \%$ \\
\hline 2006 & 7,046 & 21,419 & $24 \%$ \\
\hline 2007 & 7,042 & 21,231 & $25 \%$ \\
\hline 2008 & 6,949 & 20,628 & $25 \%$ \\
\hline 2009 & 6,958 & 20,166 & $26 \%$ \\
\hline 2010 & 7,108 & 20,162 & $26 \%$ \\
\hline 2011 & 7,088 & 19,496 & $27 \%$ \\
\hline 2012 & 7,039 & 18,956 & $27 \%$ \\
\hline 2013 & 6,714 & 18,080 & $27 \%$ \\
\hline 2014 & 6,572 & 17,212 & $28 \%$ \\
\hline 2015 & 6,606 & 16,805 & $28 \%$ \\
\hline 2016 & 6,877 & 17,091 & $29 \%$ \\
\hline 2017 & 7,238 & 17,353 & $29 \%$ \\
\hline 2018 & 8,660 & 19,820 & $30 \%$ \\
\hline 2019 & 9,263 & 20,389 & $31 \%$ \\
\hline \multicolumn{3}{|c|}{ Absolute Change (\%) } & $+9 \%$ \\
\hline
\end{tabular}

TABLE 3: R01-Equivalent Grants: Awards by Gender and Percentage to Women. (For the last fiscal year displayed, R01-equivalent grants are defined as activity codes DP1, DP2, DP5, R01, R37, R56, RF1, RL1, U01, and R35 from select NIGMS and NHGRI program announcements. Not all of these activities may be in use by the NIH every year.)

NIGMS, National Institute of General Medical Sciences; NHGRI, National Human Genome Research Institute; NIH, National Institutes of Health

In a comparison of R01 grant funding in current and constant dollars, the total funding amount for women was greater in 2019, which is an improvement from 1998. In 1998, men received higher funding amounts in both current and constant dollars (Table 4). 


\section{Cureus}

\begin{tabular}{|c|c|c|c|c|}
\hline \multirow{2}{*}{ Year } & \multicolumn{2}{|c|}{ Current Dollars } & \multicolumn{2}{|c|}{ Constant Dollars (1998) } \\
\hline & Women & Men & Women & Men \\
\hline 1998 & $\$ 240,912$ & $\$ 247,820$ & $\$ 240,912$ & $\$ 247,820$ \\
\hline 1999 & $\$ 261,864$ & $\$ 262,583$ & $\$ 253,744$ & $\$ 254,441$ \\
\hline 2000 & $\$ 284,727$ & $\$ 281,903$ & $\$ 266,054$ & $\$ 263,415$ \\
\hline 2001 & $\$ 308,613$ & $\$ 302,894$ & $\$ 279,161$ & $\$ 273,988$ \\
\hline 2002 & $\$ 329,186$ & $\$ 323,274$ & $\$ 288,259$ & $\$ 283,082$ \\
\hline 2003 & $\$ 349,085$ & $\$ 338,870$ & $\$ 295,346$ & $\$ 286,704$ \\
\hline 2004 & $\$ 358,540$ & $\$ 350,462$ & $\$ 292,523$ & $\$ 285,932$ \\
\hline 2005 & $\$ 367,410$ & $\$ 359,970$ & $\$ 288,508$ & $\$ 282,665$ \\
\hline 2006 & $\$ 367,326$ & $\$ 359,554$ & $\$ 275,757$ & $\$ 269,922$ \\
\hline 2007 & $\$ 371,142$ & $\$ 360,291$ & $\$ 268,422$ & $\$ 260,574$ \\
\hline 2008 & $\$ 384,534$ & $\$ 370,403$ & $\$ 265,623$ & $\$ 255,862$ \\
\hline 2009 & $\$ 400,568$ & $\$ 384,358$ & $\$ 268,900$ & $\$ 258,019$ \\
\hline 2010 & $\$ 413,027$ & $\$ 395,426$ & $\$ 269,712$ & $\$ 258,218$ \\
\hline 2011 & $\$ 417,379$ & $\$ 400,785$ & $\$ 264,873$ & $\$ 254,342$ \\
\hline 2012 & $\$ 430,065$ & $\$ 410,383$ & $\$ 275,178$ & $\$ 262,585$ \\
\hline 2013 & $\$ 415,576$ & $\$ 398,015$ & $\$ 261,407$ & $\$ 250,360$ \\
\hline 2014 & $\$ 442,529$ & $\$ 421,615$ & $\$ 266,229$ & $\$ 253,647$ \\
\hline 2015 & $\$ 450,840$ & $\$ 429,555$ & $\$ 265,297$ & $\$ 252,772$ \\
\hline 2016 & $\$ 478,624$ & $\$ 450,130$ & $\$ 275,647$ & $\$ 259,237$ \\
\hline 2017 & $\$ 505,649$ & $\$ 472,930$ & $\$ 283,828$ & $\$ 265,462$ \\
\hline 2018 & $\$ 547,492$ & $\$ 528,776$ & $\$ 299,279$ & $\$ 289,048$ \\
\hline 2019 & , 094 & $\$ 541,184$ & NA & NA \\
\hline
\end{tabular}

TABLE 4: R01-Equivalent Grants: Average Funding in Current and Constant Dollars, by Gender. (Current dollars and constant dollars represent average costs. Constant dollars were computed using 1998 as the base from the BRDPI based on the latest FY. Constant dollar figures were not yet available for FY2019. For the last FY displayed, R01-equivalent grants are defined as activity codes DP1, DP2, DP5, R01, R37, R56, RF1, RL1, U01, and R35 from select NIGMS and NHGRI program announcements. Not all of these activities may be in use by the NIH every year.)

BRDPI, Biomedical Research and Development Price Index; FY, fiscal year; NIGMS, National Institute of General Medical Sciences; NHGRI, National Human Genome Research Institute; NIH, National Institutes of Health

When examining trend by the application type of R01 grants, women had a small decrease in the success rates for both Type 1/New and Type 2/Renewal types of R01 grants, thus showing an overall better success rate in women for Type 1/New R01 grants and in men for Type 2/Renewal R01 grants (Table 5). 


\section{Cureus}

\begin{tabular}{|c|c|c|c|c|}
\hline Year & Women, New (Type 1) & Men, New (Type 1) & Women, Renewal (Type 2) & Men, Renewal (Type 2) \\
\hline 1998 & $28 \%$ & $28 \%$ & $44 \%$ & $52 \%$ \\
\hline 1999 & $28 \%$ & $30 \%$ & $50 \%$ & $56 \%$ \\
\hline 2000 & $29 \%$ & $30 \%$ & $46 \%$ & $54 \%$ \\
\hline 2001 & $28 \%$ & $29 \%$ & $50 \%$ & $54 \%$ \\
\hline 2002 & $26 \%$ & $29 \%$ & $46 \%$ & $53 \%$ \\
\hline 2003 & $28 \%$ & $28 \%$ & $49 \%$ & $51 \%$ \\
\hline 2004 & $23 \%$ & $24 \%$ & $42 \%$ & $46 \%$ \\
\hline 2005 & $21 \%$ & $21 \%$ & $36 \%$ & $41 \%$ \\
\hline 2006 & $19 \%$ & $20 \%$ & $34 \%$ & $37 \%$ \\
\hline 2007 & $22 \%$ & $23 \%$ & $36 \%$ & $40 \%$ \\
\hline 2008 & $21 \%$ & $22 \%$ & $35 \%$ & $38 \%$ \\
\hline 2009 & $19 \%$ & $17 \%$ & $32 \%$ & $38 \%$ \\
\hline 2010 & $18 \%$ & $18 \%$ & $35 \%$ & $40 \%$ \\
\hline 2011 & $15 \%$ & $15 \%$ & $33 \%$ & $36 \%$ \\
\hline 2012 & $15 \%$ & $15 \%$ & $31 \%$ & $37 \%$ \\
\hline 2013 & $14 \%$ & $15 \%$ & $29 \%$ & $34 \%$ \\
\hline 2014 & $16 \%$ & $15 \%$ & $33 \%$ & $37 \%$ \\
\hline 2015 & $16 \%$ & $16 \%$ & $34 \%$ & $35 \%$ \\
\hline 2016 & $17 \%$ & $18 \%$ & $35 \%$ & $38 \%$ \\
\hline 2017 & $17 \%$ & $17 \%$ & $34 \%$ & $40 \%$ \\
\hline 2018 & $20 \%$ & $20 \%$ & $41 \%$ & $45 \%$ \\
\hline 2019 & $20 \%$ & $19 \%$ & $42 \%$ & $43 \%$ \\
\hline Absolute change (\%) & $8 \%$ & $-9 \%$ & $-2 \%$ & $-9 \%$ \\
\hline
\end{tabular}

TABLE 5: R01-Equivalent Grants: Success Rates, by Gender and Type of Application. (For the last fiscal year displayed, R01-equivalent grants are defined as activity codes DP1, DP2, DP5, R01, R37, R56, RF1, RL1, U01, and R35 from select NIGMS and NHGRI program announcements. Not all of these activities may be in use by the NIH every year.)

NIGMS, National Institute of General Medical Sciences; NHGRI, National Human Genome Research Institute; NIH, National Institutes of Health

\section{Discussion}

We studied gender disparity in NIH grant awards and funding from 1998 to 2019. There was an overall increase in the percentage of female awardees for all categories of RPGs from $22 \%$ to $33 \%$ between the years 1998 and 2019, with an absolute increase of $11 \%$. The number of female RPG applicants increased from 5,763 to 17,857 from 1998 to 2019 . However, the success rates for female RPG applicants decreased from 30\% to $21 \%$, with an absolute decrease of $9 \%$ for the same period. Women have made progress as recipients of various RPGs; however, the percentage of female awardees is not comparable to their representation in the population. The percentage of R01-equivalent grants awarded to women increased by approximately $22 \%$ to 31\% between 1998 and 2019, with an absolute increase of 9\% [18]. The increase in average funding in current and constant dollars for the R01-equivalent grant awarded to women also increased slightly more than their male counterparts. A study revealed that women with an MD degree were awarded larger NIH R01 grants in obstetrics and gynecology than males with an MD degree between 2008 and 2017 [20]. 
percentage of women submitting R01-new and R01-equivalent grants did not change through 2001-2003, whereas the percentage of women submitting R01 grant renewal decreased [21]. For the years 2003 to 2007, there was a significant decline in the percentage of women investigators receiving R01 grants (new and renewal) [18,21]. Analysis of the R01 program data showed that funding and success rates for new R01 awards over the past decade have been almost identical between both the genders, but women were less successful at the renewal of R01-equivalent awards [22]. Higher application and success rates have been observed for men having previous experience as NIH grantees than women at similar career points [1]. Although women secured higher numbers of R01 awards than men, men had a greater number of R01 awards than women at all times in their careers [22].

The previous studies exploring the effects of gender on NIH funding suggested contrasting results. A retrospective cohort study (1997-2007) showed that women were less likely than men to receive an R01 grant [23]. Another study analyzing the NIH data regarding contending research and training grants suggested that women were equally or more productive than men in the R01 program, both as first-time applicants and as experienced applicants submitting new applications [18]. However, experienced male researchers were more successful than female researchers for R01 Type 2 (renewal) grant submissions [22]. After controlling for all covariates, male PhDs were significantly more likely than female $\mathrm{PhDs}$ to have received at least one R01 award [24]. These findings were also consistent with another study exploring the NIH grant funding in radiology. This study observed a significant gender disparity in mean NIH grants awarded to radiology investigators for 2016-2019 inclusive ( $\$ 619,807.00$ for male $\mathrm{PhD}$ investigators compared to $\$ 158,486.00$ for female PhD investigators) [25].

Analysis of a report (2010-2014) regarding NIH peer reviewers' critique on R01 grant applications showed that gender bias existed in the peer-review process of R01 grants, particularly for R01 type 2 grants (R01renewal grants) [26-27]. Although the percentage of women who received the R01 awards has been on the rise for the last 20 years, the probable attrition in the promotion of women to senior positions can discourage women from entering and staying in academia [28]. Research has been a driving force in the advancement of medicine, and more than half of the world's funding comes from the U.S. [1]. In 2014, the R01 grant accounted for $49 \%$ of all NIH extramural funding [2]. The R01 grant is also seen as a turning point in the early career of an academician that can be utilized to promote further granting opportunities [29].

Our study revealed existing gender differences in grant awards, which, in turn, warrants further exploration and intervention. Several factors including a career change and differing grant application strategies may be involved in a high female dropoff rate at first renewal in NIH funding. Further work needs to be conducted to address the explanation why women in academic positions might not be applying or reapplying for RPGs at the same rates as men and how this pattern could be changed [1]. Furthermore, an investigation into why women receive less favorable reviews than men for renewal applications is underway [30]. Over the decade studied, a gender disparity exists in the number of total grants and award dollars that are received by primary investigators for NIH R01 grants. However, a trend has been observed for the increased funding for those women who receive an NIH R01 grant. To combat these gender disparities, further research needs to be conducted to determine the cause and implement remedial actions [29].

There are limitations to our study. In the context of gender disparity, some researchers may self-identify in a non-binary fashion. Furthermore, the data on NIH database are only comprised of information related to those who receive funding. There are no data available on the total number of applications, including male and female applicants. Therefore, the true determination of the relative success rate of male and female researchers and differences in award amounts is not possible. Also, each application for NIH funding includes various personal information such as the name, degree, position, and academic title of the researcher, among others. It is, therefore, plausible that funding decisions are made with the knowledge of an applicant's gender, although the extent to which this knowledge may affect funding decisions, whether explicitly or through implicit bias, is impossible to quantify objectively.

\section{Conclusions}

Women have made progress as recipients of various RPGs. However, the percentage of female awardees is not comparable to the higher numbers of female doctoral candidates in the U.S. Despite an overall increase in the percentage of female researchers successfully receiving NIH grants and awards, the gender disparity exists. As apparent from the increasing enrollment of women in medical schools as well as doctoral candidates, and considering the lengthy training periods, it will be a few years before we can see meaningful changes in bridging gender disparity. Therefore, further studies to examine the longitudinal trends and lag times of women dissipating the gender differences are needed. At the same time, the continued support and retention of female researchers are pivotal to further improve the future representation of women in research, and specifically at the $\mathrm{NIH}$.

\section{Additional Information}

\section{Disclosures}

Human subjects: All authors have confirmed that this study did not involve human participants or tissue. 
Animal subjects: All authors have confirmed that this study did not involve animal subjects or tissue. Conflicts of interest: In compliance with the ICMJE uniform disclosure form, all authors declare the following: Payment/services info: All authors have declared that no financial support was received from any organization for the submitted work. Financial relationships: All authors have declared that they have no financial relationships at present or within the previous three years with any organizations that might have an interest in the submitted work. Other relationships: All authors have declared that there are no other relationships or activities that could appear to have influenced the submitted work.

\section{References}

1. Hechtman LA, Moore NP, Schulkey CE, Miklos AC, Calcagno AM, Aragon R, Greenberg JH: NIH funding longevity by gender. Proc Natl Acad Sci U S A. 2018, 115:7943-8. 10.1073/pnas.1800615115

2. Riaz IB, Siddiqi R, Zahid U, et al.: Gender differences in faculty rank and leadership positions among hematologists and oncologists in the United States. JCO Oncol Pract. 2020, 16:e507-16. 10.1200/OP. 19.00255

3. Abdellatif W, Ding J, Jalal S, et al.: Leadership gender disparity within research-intensive medical schools: a transcontinental thematic analysis. J Contin Educ Health Prof. 2019, 39:243-50. 10.1097/CEH.0000000000000270

4. Survey of Doctorate Recipients Survey Year 2017 . (2017). Accessed: October 2, 2020: https://ncsesdata.nsf.gov/doctoratework/2017/.

5. Number of doctoral degrees earned in the United States from 1949/50 to 2029/30, by gender . (2019). Accessed: October 2, 2020: https://www.statista.com/statistics/185167/number-of-doctoral-degrees-bygender-since-1950\%.

6. Li SNJ, Siddiqi J, Mahmood A, Khosa F: Equity, diversity, and inclusion in academic internal medicine at US medical schools. Eur J Intern Med. 2020, 71:89-91. 10.1016/j.ejim.2019.10.027

7. Chaudhary AMD, Naveed S, Siddiqi J, Mahmood A, Khosa F: US psychiatry Faculty: academic rank, gender and racial profile. Acad Psychiatry. 2020, 44:260-6. 10.1007/s40596-020-01192-2

8. Waseem Y, Mahmood S, Siddiqi R, Usman MS, Fatima K, Acob C, Khosa F: Gender differences amongst board members of endocrinology and diabetes societies. Endocrine. 2019, 64:496-9. 10.1007/s12020-01901861-9

9. Hamidizadeh R, Jalal S, Pindiprolu B, et al.: Influences for gender disparity in the radiology societies in North America. AIR Am J Roentgenol. 2018, 211:831-8. 10.2214/AJR.18.19741

10. Shaikh AT, Farhan SA, Siddiqi R, Fatima K, Siddiqi J, Khosa F: Disparity in Leadership in neurosurgical societies: a global breakdown. World Neurosurg. 2019, 123:95-102. 10.1016/j.wneu.2018.11.145

11. Hafeez DM, Waqas A, Majeed S, et al.: Gender distribution in psychiatry journals' editorial boards worldwide Compr Psychiatry. 2019, 94:152119. 10.1016/..comppsych.2019.152119

12. Abdellatif W, Shao M, Jalal S, et al.: Novel geographic thematic study of the largest radiology societies globally: how is gender structure biased within editorial boards?. AJR Am J Roentgenol. 2019, 213:2-7. 10.2214/AJR.18.20965

13. Grants and Funding. (2020). Accessed: October 5, 2020: https://www.nih.gov/grants-funding.

14. McCarren M, Goldman S: Research leadership and investigators: gender distribution in the federal government. Am J Med. 2012, 125:811-6. 10.1016/j.amjmed.2012.03.006

15. Budget. (2020). Accessed: October 7, 2020: https://www.nih.gov/about-nih/what-we-do/budget.

16. Wadman M: Research funding: closing arguments. Nature. 2009, 457:650-5. 10.1038/457650a

17. Oh YS, Robinson V, Stanley DV, Tolunay E, Kim DY, Galis ZS: "The good old R01": challenging downward funding success trends at the National Heart, Lung, and Blood Institute. Circ Res. 2016, 118:1475-9. 10.1161/CIRCRESAHA.115.308241

18. Data by Gender. (2019). Accessed: October 7, 2020: https://report.nih.gov/nihdatabook/category/16.

19. Jutras M, Malekafzali L, Jung S, Das P, Qamar SR, Khosa F: National Institutes of Health: gender differences in radiology funding [Online ahead of print]. Acad Radiol. 2020, 10.1016/j.acra.2020.08.004

20. Berg EJ, Ashurst J: National Institutes of Health funding in obstetrics and gynecology: analysis of R01 grants by degree and gender. Cureus. 2020, 12:e8170. 10.7759/cureus.8170

21. Research Portfolio Online Reporting Tools. (2020). Accessed: October 8, 2020: https://report.nih.gov/.

22. Pohlhaus JR, Jiang H, Wagner RM, Schaffer WT, Pinn VW: Sex differences in application, success, and funding rates for NIH extramural programs. Acad Med. 2011, 86:759-67. 10.1097/ACM.0b013e31821836ff

23. Jagsi R, Motomura AR, Griffith KA, Rangarajan S, Ubel PA: Sex differences in attainment of independent funding by career development awardees. Ann Intern Med. 2009, 151:804-11. 10.7326/0003-4819-151-11200912010-00009

24. Ginther DK, Kahn S, Schaffer WT: Gender, race/ethnicity, and National Institutes of Health R01 research awards: is there evidence of a double bind for women of color?. Acad Med. 2016, 91:1098-107. 10.1097/ACM.0000000000001278

25. Niu BT, Nicolaou S, Levine D, et al.: Trends in gender and racial profiles of US Academic Radiology Faculty . I Am Coll Radiol. 2020, 17:1337-43. 10.1016/j.jacr.2020.03.019

26. Kaatz A, Lee YG, Potvien A, et al.: Analysis of National Institutes of Health R01 application critiques, impact, and criteria scores: does the sex of the principal investigator make a difference?. Acad Med. 2016, 91:1080-8. 10.1097/ACM.0000000000001272

27. Magua $\mathrm{W}$, Zhu X, Bhattacharya A, et al.: Are female applicants disadvantaged in National Institutes of Health peer review? Combining algorithmic text mining and qualitative methods to detect evaluative differences in R01 reviewers' critiques. J Womens Health (Larchmt). 2017, 26:560-7. 10.1089/jwh.2016.6021

28. Hart KL, Frangou S, Perlis RH: Gender trends in authorship in psychiatry journals from 2008 to 2018. Biol Psychiatry. 2019, 86:639-46. 10.1016/j.biopsych.2019.02.010

29. Berg EJ, Ashurst J: Patterns of recent National Institutes of Health (NIH) Funding in general surgery: analysis using the NIH RePORTER system. Cureus. 2019, 11:e4938. 10.7759/cureus.4938 


\section{Cureus}

30. Jagsi R, Guancial EA, Worobey CC, et al.: The "gender gap" in authorship of academic medical literature--a 35-year perspective. N Engl J Med. 2006, 355:281-7. 10.1056/NEJMsa053910 